\title{
Optimization and Fuel Properties of Water Degummed Linseed Biodiesel from Transesterification Process
}

\author{
Sankalp Dixit ${ }^{1}$ and Savita Dixit ${ }^{2 *}$ \\ ${ }^{1}$ Bilt Middle East LLC, UAE \\ ${ }^{2}$ Chemistry Department, Maulana Azad National Institute of Technology, Bhopal, Madhya Pradesh, India
}

\begin{abstract}
Bio-diesel has become more attractive as an alternative fuel for diesel engine because of its environmental benefits and the fact that it is made from renewable resources such as vegetable oil and animal fats by reacting them with short chain alcohols. The present research work focus on optimization of water degummed Linseed biodiesel from transesterification process which involves the exchanging of organic group R" of an ester with the organic group of alcohol R' often catalysed by the addition of an acid or base catalyst. It was found that the maximum recovery of biodiesel yield was depicted at the optimum operation conditions $(0.8 \%$ catalyst amount $\mathrm{NaOH}$, reaction time 1 hour and reaction temperature $60^{\circ} \mathrm{C}$ ). The comparison with the fuel properties of conventional diesel, especially with regards to kinematic viscosity and carbon residue, oil needs to purify through the degumming process to remove the gums before use in biodiesel production. The effect of degumming on fuel properties of water degummed Linseed methyl ester and their different diesel blends are discussed in this paper.
\end{abstract}

Keywords: Alkaline catalyst; Biodiesel; Degumming; Water degummed linseed oil; Transesterification

\section{Introduction}

Biodiesel refers to a vegetable oil- or animal fat based diesel fuel consisting of long chain alkyl (Methyl, ethyl or propyl) esters suitable for use in diesel engines [1]. It is an alternative diesel fuel, made from renewable biological sources such as vegetable oils and animal fats [2]. The concept for producing fuel from vegetable oil for diesel engine is not radically new concept [3]. The use of vegetable oils was commenced by the inventor of the diesel engine, Rudolph diesel who first tested peanut oil in his compression ignition engine [4]. Mostly bio-diesel is prepared from oils like soybean, rapeseed, sunflower, safflower, etc. Few attempts have been made for producing bio-diesel with non-edible oils like karanj, jatropha and linseed oil through the chemical reaction of transesterification [5]. Transesterification refers to a catalyst (KOH/ $\mathrm{NaOH}$ ) chemical reaction involving oil/fat (triglyceride) and an alcohol (methyl/ethanol) to yield fatty acid alkyl esters (bio-diesel) and glycerol, shown in Figure 1 [3]. The problem of high viscosity and cold flow proper-ties of Bio-diesel or vegetable oils has been approached in several ways, such as preheating the oils, transesterification and Diesel blending. Bio-diesel or Vegetable oils also introduced the development of gumming, the formation of injector deposits, sticking as well as their compatibility with conventional lubricating oils. Plant oils contain highly variable amounts of gums. Gums can settle out in storage tanks or tank cars during storage or shipment forming a

\section{Transesterification:}

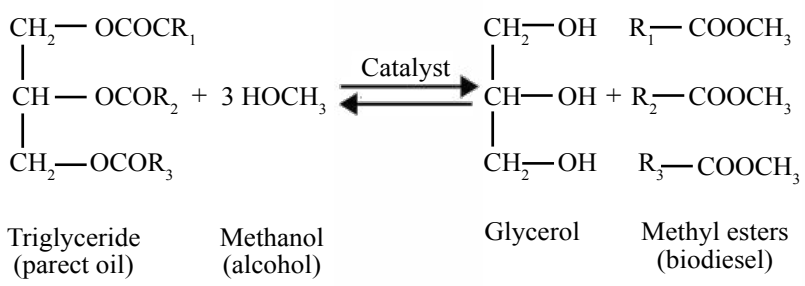

Figure 1: Transesterification reaction. difficult to removed gelatinous layer [6]. The proposed research work focus on the production of biodiesel from water degummed linseed oil without losses of oil yield. Linum usitatissimum commonly known as linseed, flaxseed, lint bells or winterlien belongs to the family Linaceae. This annual herb can grow up $60 \mathrm{~cm}$ in height in most temperate and tropical regions and the seed contain $30-40 \%$ oil, including palmitic acid (4-6\%), stearic acid (5-6\%), oleic acid (15-17\%) linoleic acid (14$16 \%)$ and linolenic acid (50-58\%) [6]. The feed oil contains impurities like phosphorus, free fatty acid, moisture which are unfavourable for biodiesel production. Such impurities reduce biodiesel yield. The feed oils were, thus pretreated to remove phosphorus (degumming), free fatty acid (deacidification) and water, before sent to transesterification. Vegetable oils contain complex organo-phosphorus compound referred to as phospholipids (phosphatides). Phosphorus and fatty acids convert into pasty substances called gums. All Vegetable Oils contains two types of gums (phospholipids), hydratable (HPL) and non-hydratable (NHPL), and they are removed from oil by degumming process. The level of hydratable and nonhydratable gums vary depending on a number of factors such as seed quality, seed type and oil milling conditions, but crude vegetable oil contains roughly $90 \%$ hydratable gums while the remaining $10 \%$ consists of non-hydratables [7]. During water degumming the hydratable Phospholipids react with water and covert into the gum phase. Present work is related to the optimization of transesterification process using water degummed linseed oil with two variable process parameters: reaction time and reaction catalyst, and also the effect of degumming on fuel properties of water degummed Linseed methyl ester.

*Corresponding author: Savita Dixit, Professor of Chemistry Department, Maulana Azad National Institute of Technology, Bhopal, Madhya Pradesh, India, Tel: +917552428155; E-mail: savitadixit1@yahoo.com

Received May 30, 2016; Accepted June 20, 2016; Published June 27, 2016

Citation: Dixit S, Dixit S (2016) Optimization and Fuel Properties of Water Degummed Linseed Biodiesel from Transesterification Process. Chem Sci J 7: 131. doi:10.4172/2150-3494.1000131

Copyright: (c) 2016 Dixit S, et al. This is an open-access article distributed under the terms of the Creative Commons Attribution License, which permits unrestricted use, distribution, and reproduction in any medium, provided the original author and source are credited. 
Citation: Dixit S, Dixit S (2016) Optimization and Fuel Properties of Water Degummed Linseed Biodiesel from Transesterification Process. Chem Sci J 7: 131. doi:10.4172/2150-3494.1000131

\section{Physio-chemical properties of linseed oil}

Physico-chemical characteristics conducted to evaluate the quality of obtained biodiesel. The flash point is defined as the minimum temperature at which the liquid produces a sufficient con-centration of vapor above it that it forms an ignitable mixture with air. The lower the flash point is, the greater the fire hazard is. Flash point can indicate the possible presence of highly volatile and flammable material in relatively nonvolatile material [8]. The flash and fire point for pure biodiesel is much higher than for petroleum diesel. It is an important factor to consider in the handling, storage and safety of fuels and flammable materials [9]. Cloud and pour point are criterion used for low temperature performance of fuel [10]. Calorific value of a fuel is the quantity of heat produced by its combustion. Density is an important parameter for diesel fuel injection system. It is the weight of a unit volume of fluid [11]. The fuel density has a great influence on the atomization process [12]. The cold flow properties determine the temperature range where biodiesel could be used without freezing inside the engine the kinematic viscosity test measure the Newtonian flow resistance imposed by the fluid [13].

\section{Experimental Procedure}

\section{Materials}

Crude linseed oil, water as a degumming agent, chemical reagent $(\mathrm{NaOH}$, methanol) of analytical grade.

\section{Methods}

Preparation of bio-diesel from water degummed linseed oil: Biodiesel was produced from water degummed linseed oil by using base catalyst transesterification process. Biodiesel yield recovery by transesterification method carried out at different reaction time and different reaction catalyst. The reaction temperature $\left(60^{\circ} \mathrm{C}\right)$ and settling time (24 hour) was kept constant in all 15 experimental run.

\section{Water degumming}

A calculated amount of crude linseed oil was taken into the reaction flask and supplemented with different wt $\%$ of hot water $(2 \%, 5 \%, 8 \%)$. Reaction mixture was heated on a hot plate at a various temperature of $\left(45^{\circ} \mathrm{C}, 55^{\circ} \mathrm{C}\right.$, and $\left.65^{\circ} \mathrm{C}\right)$ for 15 minutes accompanied with slow stirring 12 experiments were repeated at same operating conditions. After blending, it is kept overnight for the compound to settle down in order to get clean decant which is followed by separation of Gums by centrifuge tubes at $4500 \mathrm{rpm}$. After centrifuging (Figures 2 and 3), the quantity of the bottom layer (the gums layer) was measured in the centrifuge tube. This represents an easy to screen to approximate yield loss for the degumming process.

\section{Transesterification}

Take first $25 \%$ methanol (99.9\% pure) and (0.4, 0.8 and $1 \mathrm{wt} \%)$ sodium hydroxide in a strong glass bottle. Then the compound is stirred thoroughly. It takes about 15 minutes for the mixture to conflate accompanied by fleeing of hot fumes. The product of the compound so formed is sodium methoxide. Meanwhile one litter of water degummed linseed oil is taken separately in a glass bottle and heated on a hot plate to about $55^{\circ} \mathrm{C}$. Then, sodium methoxide and hot oil is mixed and stirred well for about reaction time $(0.5,1,1.5,2$ and 2.5) hour at reaction temperature i.e., $60^{\circ} \mathrm{C}$ as shown in Figures 4 and 5. After 24 hours we found a clear reddish liquid on the top with heavy black glycerin settling out at the bottom (Figure 6). Now biodiesel is separated manually from glycerin with a separating funnel. The methyl ester is

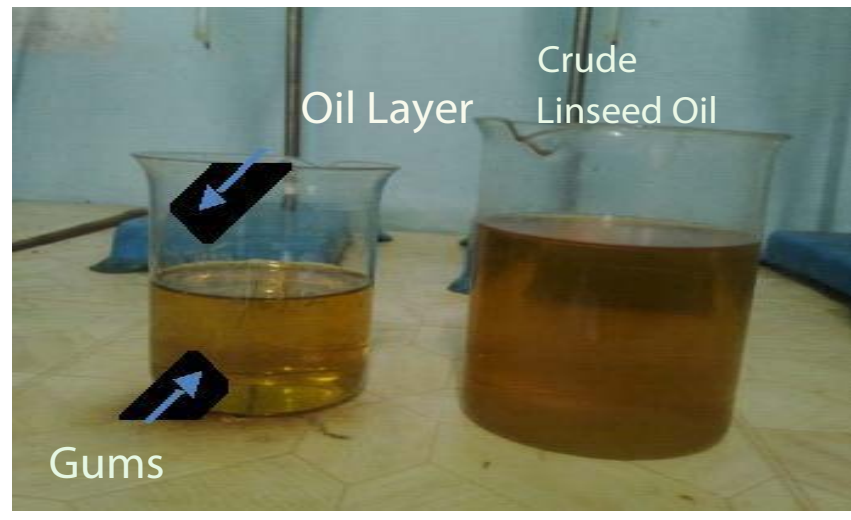

Figure 2: Oil layer and Crude Linseed oil.

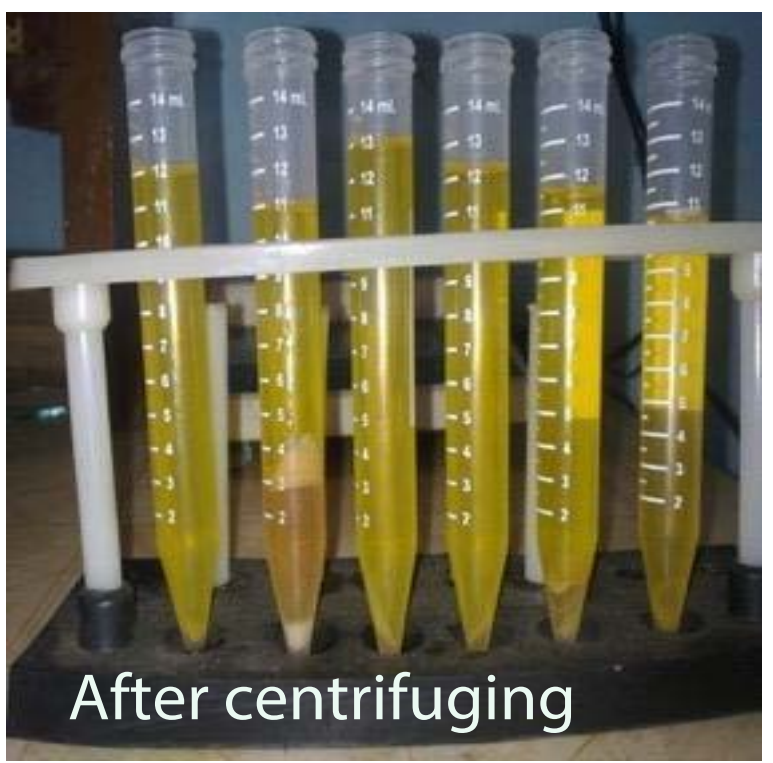

Figure 3: The bottom layer after centrifuging.

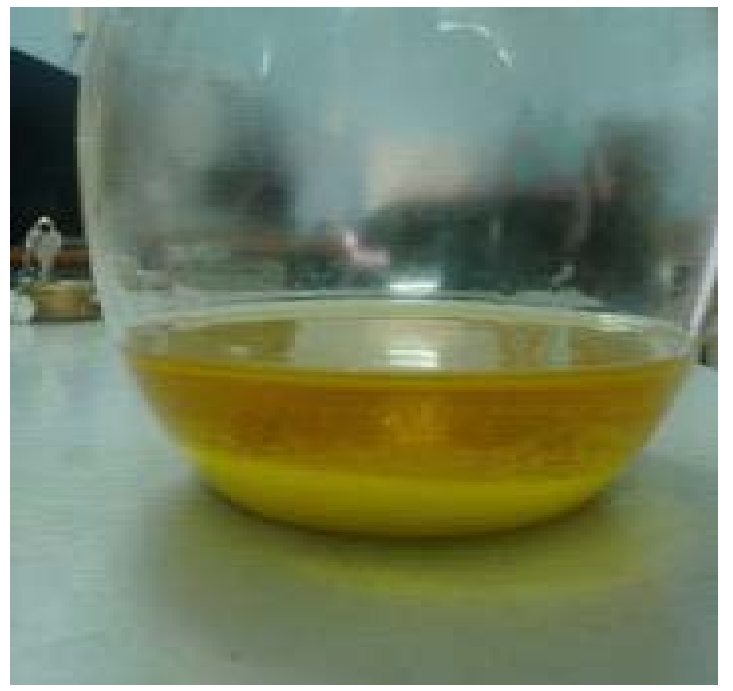

Figure 4: Sodium hydroxide in a strong glass bottle. 


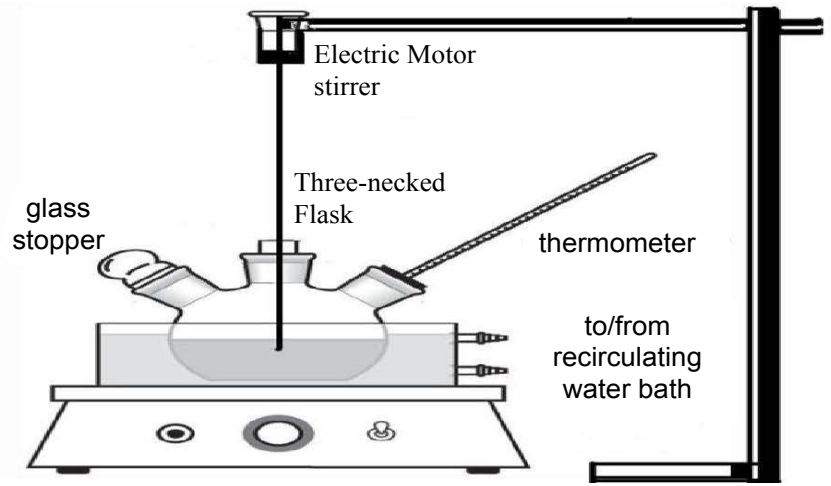

Figure 5: Transesterification reaction experimental setup.

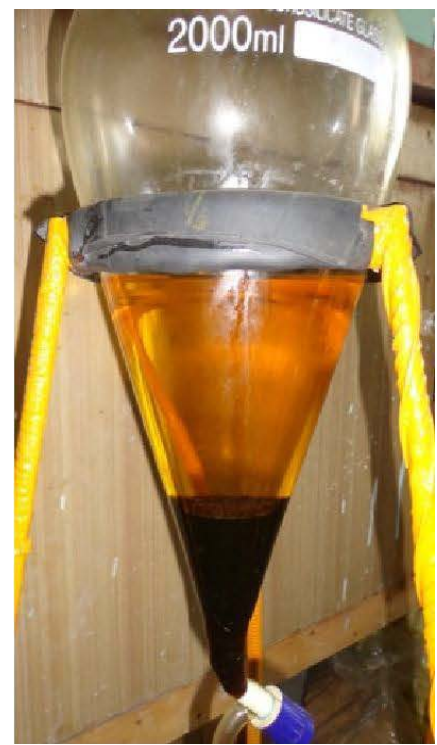

Figure 6: Biodiesel with glycerol.

purified by distillation of the un-reacted methanol under atmospheric pressure, washing several times with hot distilled water (Figures 7 and 8), accompanied by centrifugation and drying. We applied the same procedure for non-degummed linseed oil for biodiesel production and observations were made accordingly.

\section{Results and Discussion}

\section{Effect of reaction time on biodiesel yield}

In Figure 9 shows the change in Ester yield for different reaction times at a constant temperature of $60^{\circ} \mathrm{C}$ with a fixed amount of catalyst. The graph depicted the maximum ester yield for both oils at the same reaction time and the evaluation of biodiesel yield with different reaction time shows that when it was increased beyond one hour, the biodiesel yield decreased. It was found that the maximum conversion efficiency was achieved at one hour reaction time, i.e., the maximum yield was obtained at the reaction time of 1 hour.

\section{Effect of catalyst amount on biodiesel yield}

In Figure 10 shows the effect of the \% of catalyst amount on biodiesel yield for a constant reaction time of one hour at a fixed temperature of about $60^{\circ} \mathrm{C}$. It was found that the maximum biodiesel recovery from non-degummed linseed oil and water degummed linseed oil were obtained at $0.8 \mathrm{wt} \%$ catalyst amount. It was also observed that biodiesel yield started decreasing on increasing the catalyst content of the reaction. The Table 1 shows the fuel properties of methyl ester (biodiesel) obtained from WDLME and NDLO, compared with diesel fuel.

\section{Flash point and fire point}

The flash point of methyl esters are much higher than those of diesel fuels and range from 64 to 175 as shown in Figure 11. The flash point of WDLME25 does not change mostly up to $25 \%$ blend. However, the flash points increase significantly for the blends including 50\%, 75\% and $100 \%$ methyl ester. It was found that similar trend in NDLME and its diesel blends.

\section{Fire point}

It was found that similar trend in case of Fire point of WDLME and NDLME given in Figure 12.

\section{Cloud point and pour point}

From Figures 13 and 14, it was found that the cloud point WDLME, NDLME and diesel are $-4,-3$ and -8 respectively and Cloud point for

\begin{tabular}{|c|c|c|c|c|}
\hline Properties & Diesel & Linseed oil & WDLB 100 & NDLB 100 \\
\hline Density at 15 & 0.816 & 0.922 & 0.876 & 0.882 \\
\hline $\begin{array}{c}\text { Kinematic viscosity at cSt } \\
\text { at } 40\end{array}$ & 2.3 & 25.7 & 3 & 3.1 \\
\hline Flash point & 56 & 230 & 170 & 175 \\
\hline Fire point & 68 & 241 & 175 & 176 \\
\hline Cloud point & -8 & 1.7 & -4 & -3 \\
\hline
\end{tabular}

Table 1: Evaluated fuel properties of Test Fuels.

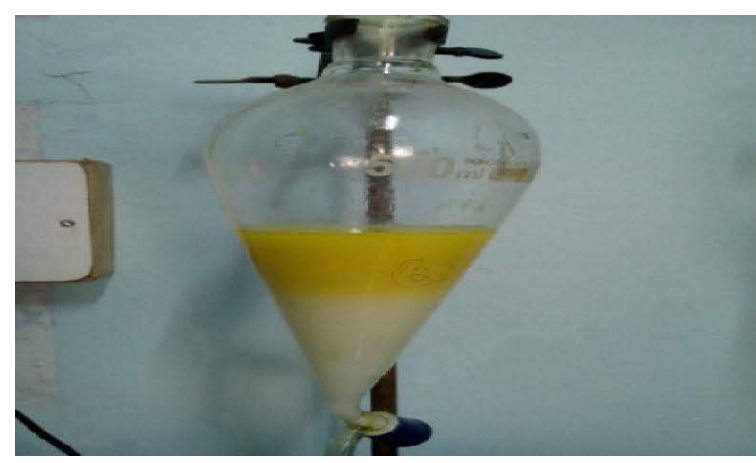

Figure 7: Washing with Final product hot distilled.

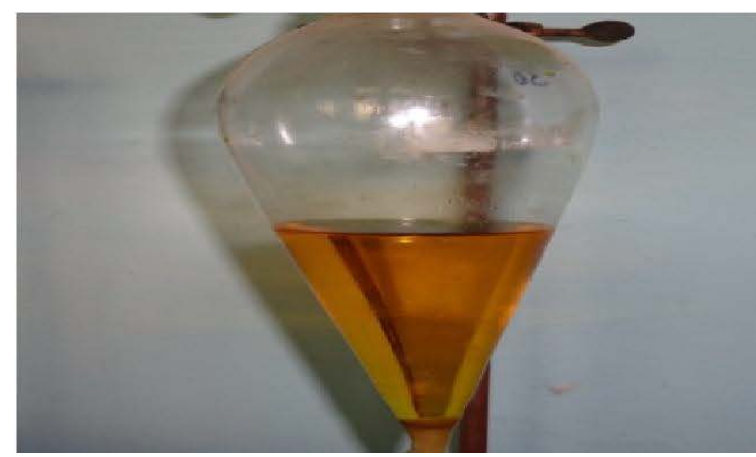

Figure 8: Biodiesel. 


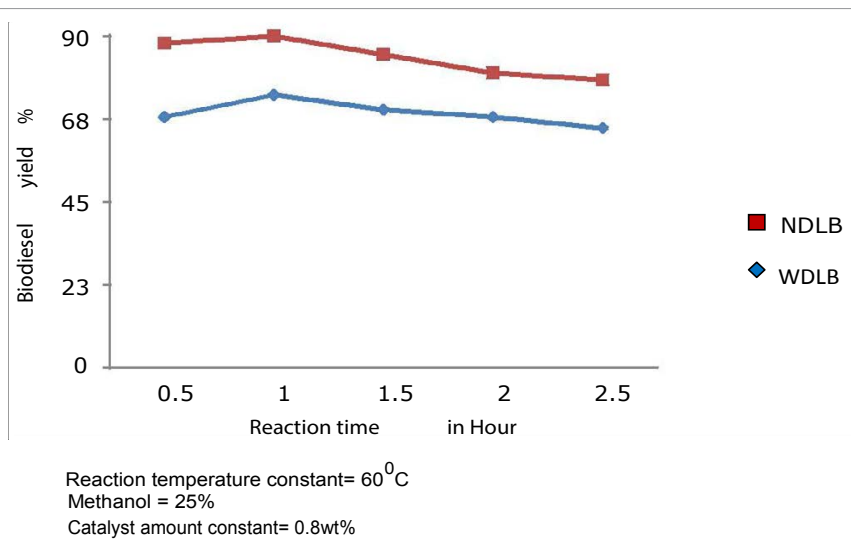

Figure 9: Effect of reaction time on biodiesel yield.

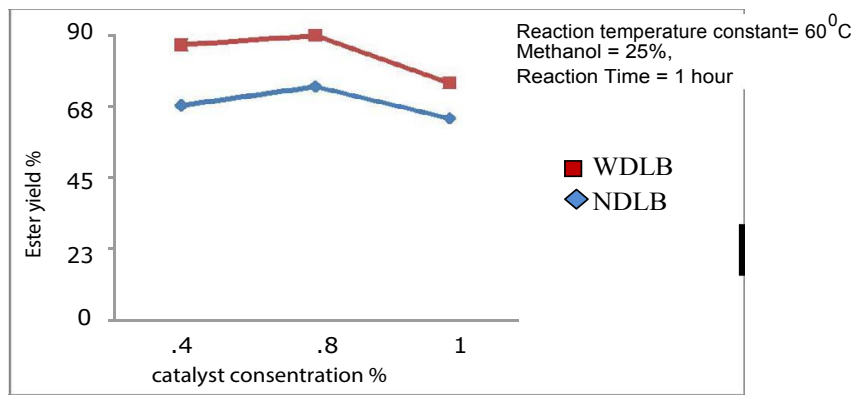

Figure 10: Effect of catalyst amount on biodiesel yield.

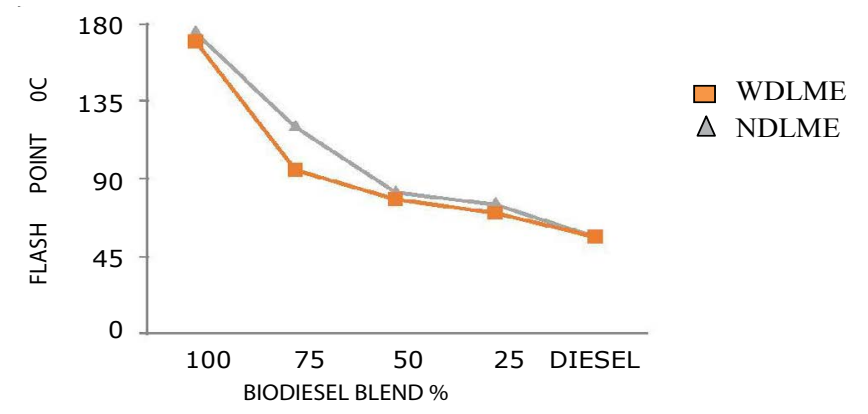

Figure 11: Flash points of methyl ester-diesel fuel blends.

WDLME25, WDLME50, WDLME75 and WDLME100 is decreased by $-6,-5,-5$ and -4 respectively whereas the corresponding methyl esters had Pour point of $-14,-14,-13$ and -10 . Cloud Point for NDLME25, NDLME50, NDLME75 and NDLME100 is increased by $-5,-4,-4$ and -3 respectively whereas the corresponding methyl esters had Pour point of $-13,-13,-10$ and -9 .

\section{Viscosity}

The viscosity of a fuel is important property which is affecting the atomization of the fuel during the injection. The high viscosity of plant oil was reported to be the main cause of injector chocking problem in C.I. engine [13]. The Figure 15 shows that the variation of viscosity plotted against different diesel blends of enzymatic degummed Linseed oil methyl ester compared with diesel fuel. Kinematic viscosity for WDLME25, WDLME50, WDLME75 and WDLME100 is higher by $8.33 \%, 16.6 \%, 20.83 \%$ and $25 \%$ respectively, as compared to diesel at the 40 temperature. Kinematic viscosity for NDLME25, NDLME50,
NDLME75 and NDLME 100 is higher by $16.6 \%, 20.83 \%, 29.16 \%$ and $45.83 \%$ respectively, as compared to diesel at the 40 temperature. Hence, the WDLME25 gives lower viscosity as compared to other methyl ester blends and it is much closer to diesel fuel.

The calorific value of WDLME25, WDLME50, WDLME75 and WDLME100 is lower by and $1.7 \%, 3.5 \%, 3.95 \%$ and $5.92 \%$, respectively compared to diesel. NDLME25, NDLME50, NDLME75 and NDLME100 are lower by and $1.9 \%, 3.7 \%, 4.1 \%$ and $7.67 \%$, respectively compared to diesel. Hence the calorific value increased with decreasing concentration of methyl ester in blends. The reason can be attributed to the oxygen content in methyl ester (biodiesel) improves its combustion efficiency due to an increase in the homogeneity of oxygen with the fuel during combustion. Because of this the combustion efficiency of biodiesel is higher than that of petro-diesel.

\section{Density}

It is an important parameter for diesel fuel injection system. It is the weight of a unit volume of fluid [14]. The fuel density has a great influence on the atomization process [15]. The Figures 16 and 17 shows

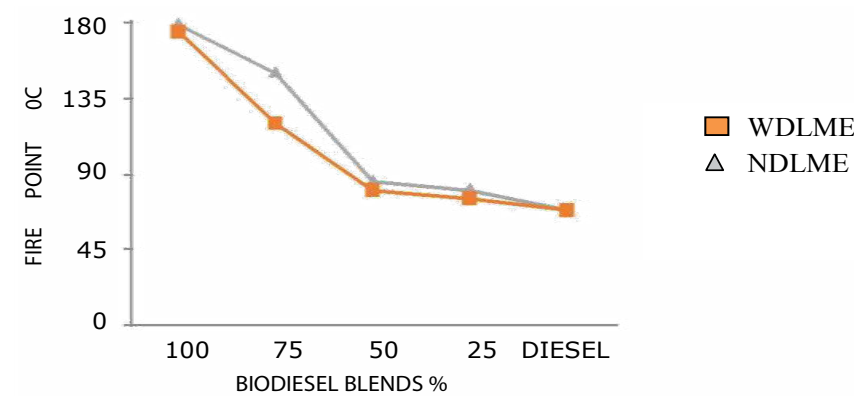

Figure 12: Fire points of methyl ester-diesel fuel blends.

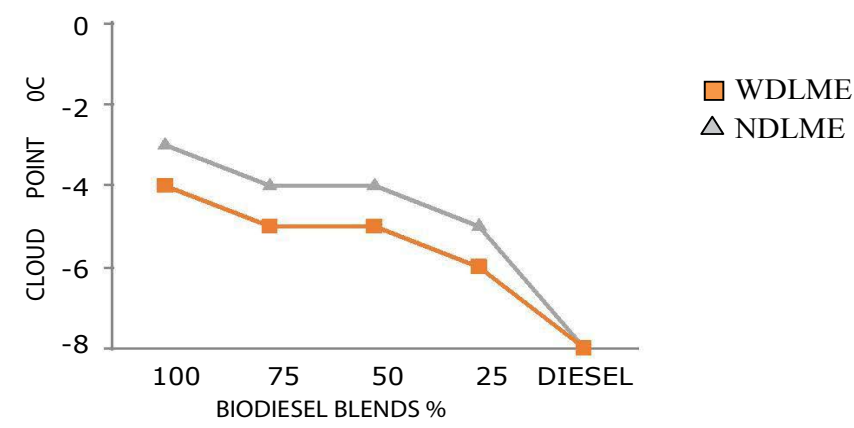

Figure 13: Cloud point of biodiesel-diesel fuel blends.

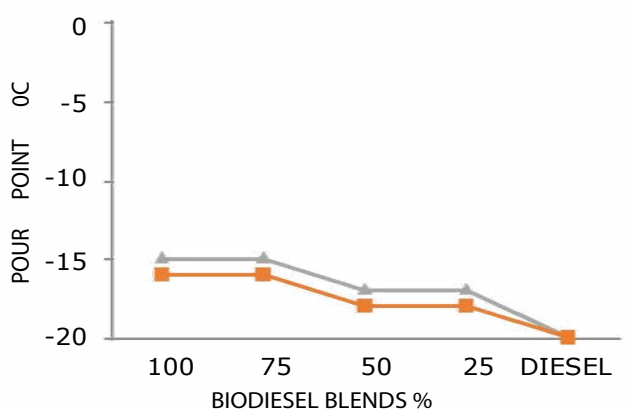

$\square$ WDLME

$\triangle \mathrm{NDLME}$

Figure 14: Pour point of biodiesel -diesel fuel blends. 


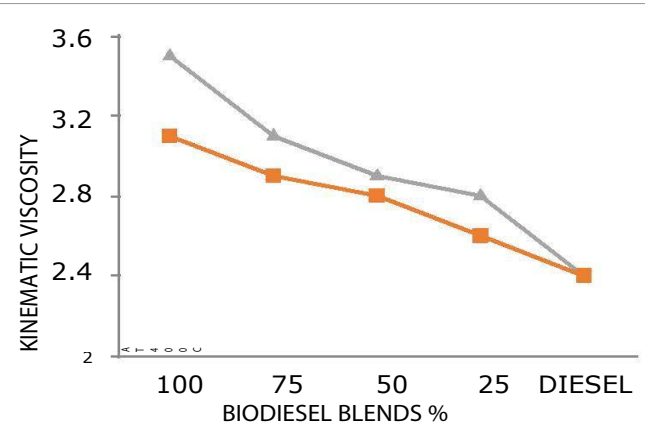

$\square$ WDLME $\triangle$ NDLME

Figure 15: Variations in kinematic viscosity Linseed oil methyl esters and thei blends.

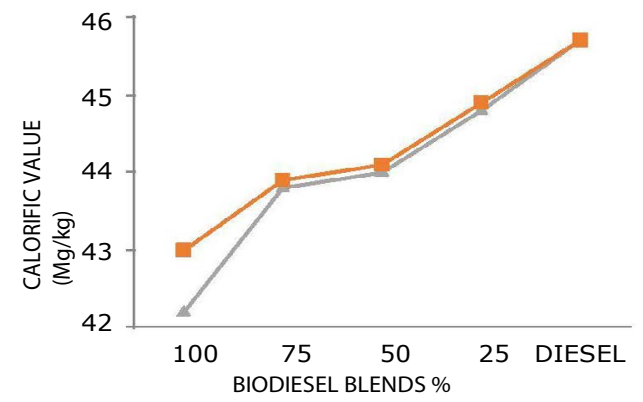

$\square$ WDLME

$\triangle \mathrm{NDLME}$

Figure 16: Variation in calorific value of Linseed oil methyl ester and their different blends.

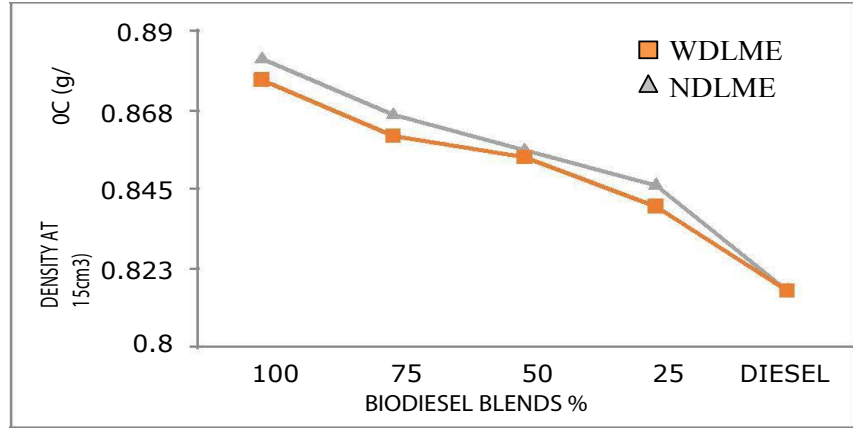

Figure 17: Variation in density of Linseed oil methyl ester and their different blends.

\begin{tabular}{|c|c|}
\hline Oil sample & Phosphorus (ppm) \\
\hline Linseed oil & 150 \\
\hline Water degummed Linseed oil & 10.5 \\
\hline
\end{tabular}

Table 2: Phosphorus content of Linseed oil samples.

the variation in density of WDLME100, NDLME100 and diesel were $0.876 \mathrm{~g} / \mathrm{cm}^{3}, 0.882 \mathrm{~g} / \mathrm{cm}^{3}$ and $0.816 \mathrm{~g} / \mathrm{cm}^{3}$ respectively, and Density for WDLME25, WDLME50, WDLME75 and WDLME100 is increased by $2.94 \%, 4.6 \%, 6.172 \%$ and $7.352 \%$ respectively, as compared to diesel at 15. Density for NDLME25, NDLME50, NDLME75 and NDLME100 is increased by $3.67 \%, 4.90 \%, 6.1 \%$ and $8.08 \%$ respectively as compared to diesel at 15 .

\section{Conclusion}

It was found that the minimum phosphorus yield was depicted at optimum operating conditions $\left(5 \%\right.$ hot water, $55^{\circ} \mathrm{C}$ reaction temperature and 15 minute reaction time) shown in Table 2. Lowest phosphorus content of Linseed oil sample was selected as feedstocks for biodiesel production. It was found that the maximum recovery of biodiesel yield was depicted at the optimum operation conditions $(0.8 \%$ catalyst amount $\mathrm{NaOH}$, reaction time 1 hour and reaction temperature $60^{\circ} \mathrm{C}$ ). It was also investigated that Water degummed linseed oil gives higher yield (90\%) as compared to non-degummed linseed oil (74\%). The experiments were repeated in 15 times at the same operating conditions. WDLO (water degummed linseed oil) gives 16\% higher yield of biodiesel as compared to NDLO (non-degummed linseed oil) is used as feedstock for biodiesel production.

The important conclusions from the variation in properties of linseed oil methyl ester and their blends are as follows:

1. The fatty acid distribution of feedstock's has an effect on the cloud and pour point. The cloud point for NDLME100 and NDLME25 are $3^{\circ} \mathrm{C}$ and $-5^{\circ} \mathrm{C}$ respectively. The pour point for WDLME100, and NDLME25 is $-15^{\circ} \mathrm{C}$, and $-17^{\circ} \mathrm{C}$ respectively. Hence the cloud and pour point of WDLME25 comparable to that of diesel fuel.

2. The calorific value of diesel, WDLME100, NDLME100, WDLME25 and NDLME25 were found $43.5 \mathrm{MJ} / \mathrm{kg}, 43.0 \mathrm{MJ} / \mathrm{kg}, 45.0 \mathrm{MJ} / \mathrm{kg}$ and $44.9 \mathrm{MJ} / \mathrm{kg}$ respectively. The calorific value of WDLME25 is $1.5 \%$ lower than diesel and it may be comparable to that of diesel fuel.

3. The flash point for methyl esters of water degummed and nondegummed Linseed oil is $170^{\circ} \mathrm{C}$ and $175^{\circ} \mathrm{C}$ much higher than those of diesel fuels bit its diesel blends WDLME25 and NDLME25 is $70^{\circ} \mathrm{C}$ and $75^{\circ} \mathrm{C}$. The flash point of WDLME25 very closed to diesel fuel.

4. It was found that kinematic viscosity for WDLME100, NDLME100, WDLME25 and NDLME25 is higher by $25.0 \%, 45.83 \%, 8.33 \%$ and $16.6 \%$ respectively as compared to diesel at the $40^{\circ} \mathrm{C}$ temperature. Hence the viscosity of WDLME25 is comparable to that of diesel fuel.

5. Density for WDLME100, NDLME100, WDLME25 and NDLME25 is higher by $7.352 \%, 8.08 \%, 2.94 \%$ and $3.67 \%$ respectively, as compared to diesel at $15^{\circ} \mathrm{C}$. WDLME 25 shows the very little difference in density with diesel fuel.

From the above conclusions it is suffice to say that in the near future water degummed linseed biodiesel as a blend can be expected as a promising alternative energy resource for diesel engine.

\section{References}

1. Savita D, Sangeeta K, Rehman A (2012) Linseed oil as a potential resource for bio-diesel: A review. Renewable and Sustainable Energy Reviews 16: 4415-4421.

2. Ma F, Hanna MA (1999) Bio-diesel production: a review. Bioresource Technology 70: 1-15.

3. Lingfa P (2011) An Experimental Evaluation of Karanja Based Biodiesel as a Supplimentary Diesel Fuel for Rural Applications.

4. Parawira W (2010) Bio-diesel production from Jatropha curcus. A review scientific Research and Essays 5: 1796-1808.

5. Vilas GS, Raheman H (2005) Biodiesel production from mahua (Madhuca indica) oil having high free fatty acids. Biomass and Bioenergy 28: 601-605.

6. Ghosh BB, Sandip Kumar H, Ahindra N (2008) Synthesis of Bio-diesel from oils of Jatropha, Karanj and Putranjiva to utilize in Ricardo engine and its performance \& Emission measurement; Proceedings of the 4th BSME-ASME International Conference on Thermal Engineering 27-29 December, 2008, Dhaka, Bangladesh.

7. Ayhan D (2009) Production of bio-diesel fuels from linseed oil using methanol and ethanol in non-catalyti SCF conditions, Biomass and Bio-energy 33: 113-118. 
Citation: Dixit S, Dixit S (2016) Optimization and Fuel Properties of Water Degummed Linseed Biodiesel from Transesterification Process. Chem Sci J 7: 131. doi:10.4172/2150-3494.1000131

Page 6 of 6

8. Rehman A, Pandey RK, Dixit S, Sarviya RM (2009) Performance and emission evaluation of diesel engine fueled with vegetable oil. International Environmental Research 3: 463-470.

9. ASTM: D2500-91 standard test method for cloud point of petroleum products An American National Standard. British Standard -4458.

10. Ragit SS (2011) Process standardization, Characterization and experimental investigation on the performance of biodiesel fuelled C.I. engine. PhD Thesis, Department of mechanical Engineering, Thapar University, Patiala, India.

11. Rao PV (2011) Experimental Investigation on the influence of properties of Jatropha biodiesel on performance, combustion and Emission Characteristics of a DI-Cl engine. International Journal of Engineering \& Applied Sciences 7: 141.
12. Giwa S, Ch L, Abdullah U, Adam NM (2010) Investigation "Egusi" (Citrullus Colocyn-this L.) Seed oil as potential biodiesel feedstock. Energies 3: 607-618.

13. Chen B, Yuqiu S, Jianhua F, Jiu W, Jiang W (2010) Cold flow properties and crystal morphologies of bio-diesel blends. Chemistry and Technology of fuels and oils 46: 52-57.

14. ASTM: D97-93 standard test method for pour point of petroleum products; An American National Standard.

15. Esteban B, Riba JR, Baquero G, Rius A, Puig R (2012) Temperature dependence of density and viscosity of vegetable oils. Biomass and Bioenergy 42: 164-171. 